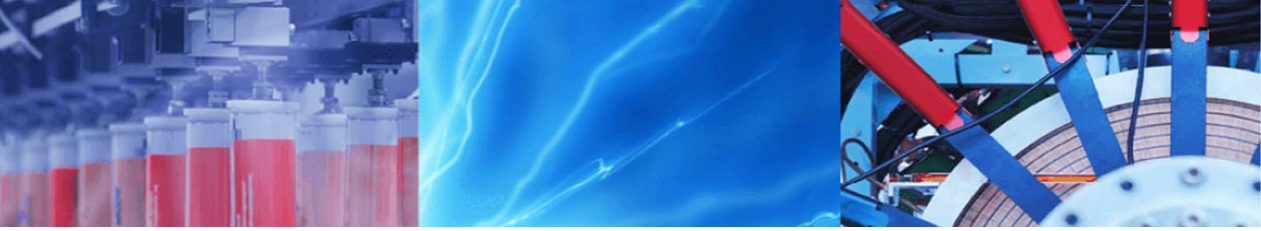

Research Article

\title{
Intercorrelation between physical and electrochemical behavior of nitrogen-doping in graphene for symmetric supercapacitor electrode
}

\author{
Rohit Yadav $^{1}$ (D) $\cdot$ Prerna Joshi $^{1} \cdot$ Masanori Hara $^{1} \cdot$ Takumi Yana $^{2} \cdot$ Satoru Hashimoto $^{2} \cdot$ Masamichi Yoshimura $^{1}$
}

Received: 17 April 2020 / Accepted: 20 August 2020 / Published online: 5 September 2020

(c) Springer Nature Switzerland AG 2020

\begin{abstract}
Graphene and heteroatom-doped graphene are potential candidates for high-performance energy storage applications, such as supercapacitors. Herein, we have studied the structure and defect generation in nitrogen-doped reduced graphene oxide $(\mathrm{N}-\mathrm{rGO})$, synthesized via pyrolysis of urea in a wide temperature range $\left(600-900{ }^{\circ} \mathrm{C}\right)$. Nitrogen-doped defect densities were analyzed in detail by the deconvolution of the Raman spectrum, where we found the importance of additional I and D" peaks. I peak is found to be sensitive to the dopant, and D" peak is consistent with the crystallinity, which are further revealed by X-ray photoelectron spectroscopy and X-ray diffraction measurements. Synthesized N-rGO was then investigated for the supercapacitor electrode. $\mathrm{N}-\mathrm{rGO}$ synthesized at $800^{\circ} \mathrm{C}$, having low crystallinity (crystallite size $3.44 \mathrm{~nm})$, highest degree of reduction $(C / O$ ratio $=23)$, high specific surface area $\left(152.3 \mathrm{~m}^{2} \mathrm{~g}^{-1}\right)$, and presence of both pseudocapacitive and electric double layer behavior, resulting in highest areal capacitance of $138.4 \mathrm{mF} \mathrm{cm}^{-2}$, lowest selfdischarge rate, and exceptional capacity retention of $121.7 \%$ after 10,000 cycles of charge-discharge. The synthesized electrode material has also been tested for a symmetric supercapacitor cell showing high specific capacitance $66.8 \mathrm{~F} \mathrm{~g}^{-1}$ in $0.5 \mathrm{M} \mathrm{H}_{2} \mathrm{SO}_{4}$ electrolyte. This study is a first of its kind of structural evaluation and Raman characterization of N-rGO for application in supercapacitor cell.
\end{abstract}

Keywords Nitrogen-doped reduced graphene oxide · Symmetric supercapacitor $\cdot$ Raman deconvolution · Areal capacitance

\section{Introduction}

Among energy storage devices, supercapacitors have attracted great interest since 1957, when General Electric patented and demonstrated their practical application [1]. Supercapacitors are classified into electric double-layer capacitors (EDLCs) [2], pseudocapacitors [3], and hybrid capacitors, on the basis of their charge storage mechanism. EDLC behavior is commonly shown by carbon-based materials, where charge storage takes place via electrolyte ion intercalation inside porous electrode materials. The intercalation of ions results in the formation of an electrostatic double layer, which leads to the charging of EDLC supercapacitor materials.

Among available carbon-based materials like carbon nanotubes (CNT), activated carbon, and graphene, graphene emerged as an appropriate candidate for EDLC electrode due to its high mechanical strength (Young's

Electronic supplementary material The online version of this article (https://doi.org/10.1007/s42452-020-03401-x) contains supplementary material, which is available to authorized users.

Rohit Yadav, sd19503@toyota-ti.ac.jp|'Graduate School of Engineering, Toyota Technological Institute, 2-12-1 Hisakata, Tempaku-ku, Nagoya 468-8511, Japan. ${ }^{2}$ Meijo Nano Carbon Co., Ltd., 2271-129 Anagahora, Shimoshidami, Moriyama, Nagoya 460-0002, Japan. 


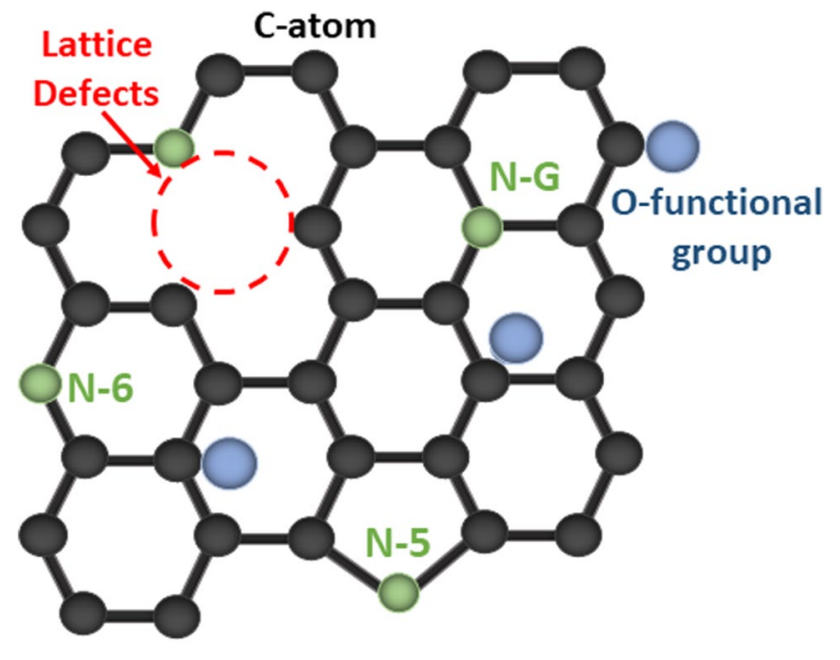

Fig. 1 Schematic of N-rGO

modulus of 2 TPa) [4], large surface area $\left(\sim 2630 \mathrm{~m}^{2} \mathrm{~g}^{-1}\right)$ [5], and high electrical conductivity $\left(\sim 510^{-3} \mathrm{~S} \mathrm{~cm}^{-1}\right)$ [6]. High mechanical strength provides structural stability to the electrode over volumetric change during electrochemical measurement [7]. The high surface area allows better electrolyte ion intercalation between graphene sheets [8], and high electrical conductivity leads to fast electrochemical kinetics [9]. Despite the excellent properties of graphene, the accessible surface area in pristine graphene depends mainly on its layered structure. The tendency of stacking of these layers will (a) limit the efficient electrolyte ion accessibility and (b) diminish the electrochemically active sites, overall lowering intrinsic capacitance as a supercapacitor electrode [10]. To overcome these limitations, theoretical and experimental studies have proved that heteroatom doping improves the electrochemical performance of graphene [11-13], by tailoring its electronic properties, preventing the stacking of sheets, and inducing defects to provide surface active sites in the lattice [14-17].

Here, nitrogen $(\mathrm{N})$ atom was chosen as dopant because of its comparable atomic size with a carbon atom, making it relatively easy for $\mathrm{N}$ to replace $\mathrm{C}$ in graphene lattice and induce defects. Further, the difference in electronegativity of $\mathrm{N}$ and $\mathrm{C}$ atoms will enable to tune the electronic properties of graphene. Nitrogen can be doped in graphene in three possible doping configurations, termed as pyrrolic $(\mathrm{N}-5)$, pyridinic $(\mathrm{N}-6)$, and quaternary nitrogen $(\mathrm{N}-\mathrm{G})$ (also shown in Fig. 1) [18]. In recent years, urea/melamine are used as eco-friendly and low-cost precursors for largescale production of nitrogen-doped reduced graphene oxide (N-rGO) $[15,16,19]$ via pyrolysis at high temperature for applications such as oxygen reduction reaction (ORR) [20], hydrogen evolution reaction (HER) [14], and batteries [21]. However, focus on short/particular temperature range and inadequate analysis in previous studies has limited the scope of urea derived graphene (heteroatom-doped graphene) to mere characterization and application $[14,15,19]$. In the present work, to investigate the correlation between structural change and supercapacitor application of $\mathrm{N}-\mathrm{rGO}$, we have (1) considered a wide temperature range $\left(600-900^{\circ} \mathrm{C}\right)$ of $\mathrm{N}-\mathrm{rGO}$ synthesis to clearly observe the generation and collapse of the $\mathrm{N}$-rGO structure simultaneously and (2) carried out Raman deconvolution to analyze the defect densities at all synthesis temperatures. Although Raman spectroscopy is a well-established tool to characterize carbon samples and their structural defects, via the appearance of conventional $D$ and $G$ peaks, a complete understanding of heteroatom doping is still challenging and requires further investigation of additional deconvoluted peaks [22], with their correlated study.

In this study, N-rGO is synthesized via pyrolysis of urea and graphene oxide (GO) within a temperature range of 600-900 ${ }^{\circ} \mathrm{C}$. X-ray diffraction and D" Raman peak supported the increased crystallinity of the samples at higher pyrolysis temperatures. However, this crystallinity was observed to have little effect on the areal capacitance. Another deconvoluted Raman peak, i.e. I peak, was found to be dopant sensitive and its correlation with X-ray photoelectron spectroscopy confirmed high nitrogen doping (15 at. \%) at $600^{\circ} \mathrm{C}$ pyrolysis temperature. However, $800^{\circ} \mathrm{C}$ was found to be the optimum temperature for designing the supercapacitor electrode possessing large surface area, high degree of reduction, low crystallinity, and the combined effect of EDLC and pseudocapacitive behavior due to attached functional groups, specially quinone.

\section{Materials and methods}

\subsection{Synthesis of Nitrogen-doped reduced graphene oxide (N-rGO)}

For N-rGO, synthesis was carried out in two steps. Firstly, graphite oxide $(\mathrm{GO})$ was synthesized using the modified Hummers' method [23]. Briefly, natural graphite of flake size $7 \mu \mathrm{m}$ (Sri Lanka natural graphite, RS Mines) was oxidized using concentrated sulphuric acid $\left(\mathrm{H}_{2} \mathrm{SO}_{4}\right.$, Wako Pure Chemical Industries Ltd.) and potassium permanganate $\left(\mathrm{KMnO}_{4}\right.$, Nacalai Tesque Inc.), followed by hydrogen peroxide $\left(\mathrm{H}_{2} \mathrm{O}_{2}\right.$, Kishida Chemical Co.). The reaction was quenched using distilled (DI) water and the resultant mixture was washed and dried to obtain GO. Obtained GO $(0.4 \mathrm{~g})$ was dissolved in $200 \mathrm{~mL}$ of DI water containing $2.8 \mathrm{~g}$ urea (GO: urea $=1: 7 \mathrm{wt} . / \mathrm{wt}$.) and the mixture solution was sonicated for $1 \mathrm{~h}$ to obtain a uniform mixture dispersion. 
The high weight ratio of GO/urea (1:7) was used to develop a clear understanding of pyrolysis temperature on doping configuration. The mixture was freeze-dried and pyrolyzed at different temperatures $\left(600,700,800\right.$, and $\left.900^{\circ} \mathrm{C}\right)$ for $1 \mathrm{~h}$ in an inert atmosphere. Then, the obtained black color products were washed thoroughly with $1 \mathrm{M} \mathrm{HCl}$ and dried in vacuum at $60^{\circ} \mathrm{C}$ for $3 \mathrm{~h}$. The synthesized samples were marked as N-rGO-6, N-rGO-7, N-rGO-8, and N-rGO-9, referring to the pyrolysis temperature of $600,700,800$, and $900^{\circ} \mathrm{C}$, respectively.

\subsection{Characterization}

X-ray diffraction (XRD) measurement was carried out to study the crystal structure and interlayer $d$ spacing with Rigaku Ultima IV X-ray Diffractometer using Cu Ka radiation source $(\lambda=1.5405 \AA)$. XRD was operated at $40 \mathrm{kV}$ and $200 \mathrm{~mA}$ with a step size of $0.02^{\circ}$ and a scan speed of $2^{\circ}$ per min with varying $2 \theta$ value from $10^{\circ}$ to $80^{\circ}$. Raman spectroscopy (In-Via Renishaw Microscope, $532 \mathrm{~nm}$ laser source) was employed to study the structural changes like restoration and degree of defects. X-ray photoelectron spectroscopy (XPS) (ULVAC-PHI 5000, monochromatic Al Ka X-ray, $1486.6 \mathrm{eV}$ ) was done to measure the chemical composition and surface functional groups in $\mathrm{N}-\mathrm{rGO}$. The XPS spectra were calibrated using an $\mathrm{sp}^{2} \mathrm{C} 1 \mathrm{~s}$ band at $284.5 \mathrm{eV}$. Morphological studies were performed by transmission electron microscopy (TEM), operated at $120 \mathrm{kV}$ using JEOL, JEM-2100 microscope. Energy-dispersive $X$-ray (EDX) spectroscopy equipped on scanning electron microscopy (SEM, SU3500, Hitachi High Technologies Co.) was operated at $15 \mathrm{kV}$ using EMAX Evolution X-Max Horiba Ltd. The Brunauer-Emmett-Teller (BET) method was applied to study nitrogen adsorption-desorption isotherm at $77 \mathrm{~K}$ using a Micromeritic TrisStar II.

\subsection{Electrochemical measurement}

The electrochemical performance of all the samples was evaluated using the HZ-7000 Hokuto Denko electrochemical measurement system in a three-electrode setup at room temperature. Pt wire was used as a counter electrode (CE), $\mathrm{Ag} / \mathrm{AgCl}$ as a reference electrode (RE), and active material coated on glassy carbon (GC) electrode $(\varphi=3 \mathrm{~mm})$ as a working electrode (WE). Electrode ink comprising of active material ( $1 \mathrm{mg} \mathrm{N}-\mathrm{rGO}$ ), DI water $(60 \mu \mathrm{L})$, isopropyl alcohol (IPA) $(40 \mu \mathrm{L})$, and $5 \mathrm{wt}$. \% Nafion as a binder was spin-coated on the GC at $400 \mathrm{rpm}$, keeping the mass loading to $1 \mathrm{mg} \mathrm{cm}^{-2}$ for all electrochemical measurements. The deposited electrode was dried in vacuum at $60^{\circ} \mathrm{C}$ for $1 \mathrm{~h}$. The electrochemical reaction on WE was measured by cyclic voltammetry (CV) at a scan rate of $5 \mathrm{mV} \mathrm{s}^{-1}$ in an aqueous $0.5 \mathrm{M} \mathrm{H}_{2} \mathrm{SO}_{4}$ solution. In the present study, the aqueous electrolyte was mainly focused because of its high ionic conductivity (that will lead to high power density), low cost, convenient storage (can store in the ambient environment), and environment-friendly nature (non-flammable and does not produce harmful byproducts). Areal capacitance was calculated from $C=\frac{I \Delta T}{A \Delta V^{\prime}}$ where I refers to charge/discharge current, $\Delta T$ is discharge time, $\mathrm{A}$ is the area of the deposited electrode and $\Delta \mathrm{V}$ is the potential window for charge/discharge measurement.

For symmetric cell measurement, the same amount of electrode ink was drop-casted on two cleaned stainless steel substrates. Prior to measurement, the Whatman filter paper was soaked in $0.5 \mathrm{M} \mathrm{H}_{2} \mathrm{SO}_{4}$ electrolyte overnight, and the filter paper was used as a separator in the cell. The soaked filter paper was sandwiched between both deposited electrodes and electrode connections were made by spot welding stainless steel wire at both electrodes. Specific capacitance was calculated from galvanostatic charge-discharge (GCD) curve using formula $C=\frac{1 \Delta T}{m \Delta V^{\prime}}$ where $m$ is the mass of active material deposited.

\section{Results and discussion}

\subsection{Material characterization}

The oxidation of graphite to $\mathrm{GO}$ and simultaneous reduction and $\mathrm{N}$ doping to $\mathrm{N}-\mathrm{rGO}$ were investigated by XRD analysis (Fig. 2). The synthesis of GO with the interlayer spacing of $d=0.89 \mathrm{~nm}$ by the modified Hummers' method was confirmed by the peak position of (002) plane at $9.9^{\circ}$. The high lattice spacing in $\mathrm{GO}$ comes from the expansion of basal plane due to the formation of GO sheets modified with oxygen functional groups and intercalated water molecules between the sheets, as reported in the literature $[24,25]$. The highly intense and sharp peak of $G O$ is attributed to the ordered stacking of $\mathrm{GO}$ sheets along the c-axis [26]. On the other hand, N-rGO synthesis is certified from the peak position shift of (002) plane to a higher value for all the samples, as shown in Fig. 2. After pyrolysis, interlayer $\mathrm{d}$ spacing of $\mathrm{N}-\mathrm{rGO}$ samples was decreased due to the removal of the water molecule and oxygen functional groups. In addition, the increased peak intensity and peak sharpness for the (002) plane was observed with an increase in pyrolysis temperature (Fig. 2b). The peak shape change suggests overlapped $\mathrm{N}-\mathrm{rGO}$ sheets along c-axis [27] and increased crystallinity of the sample at higher temperatures [16]. This is consistent with the calculated crystallite size along the c-axis $\left(L_{c}\right)$ (Table 1$)$ using Scherrer's equation, with dimensionless shape factor, $\mathrm{K}=0.89$ $[19,28]$. The XRD analysis exhibits that the $\mathrm{N}-\mathrm{rGO}-9$ is more crystalline and has a large $L_{c}$ as compare to other $\mathrm{N}-\mathrm{rGO}$ 

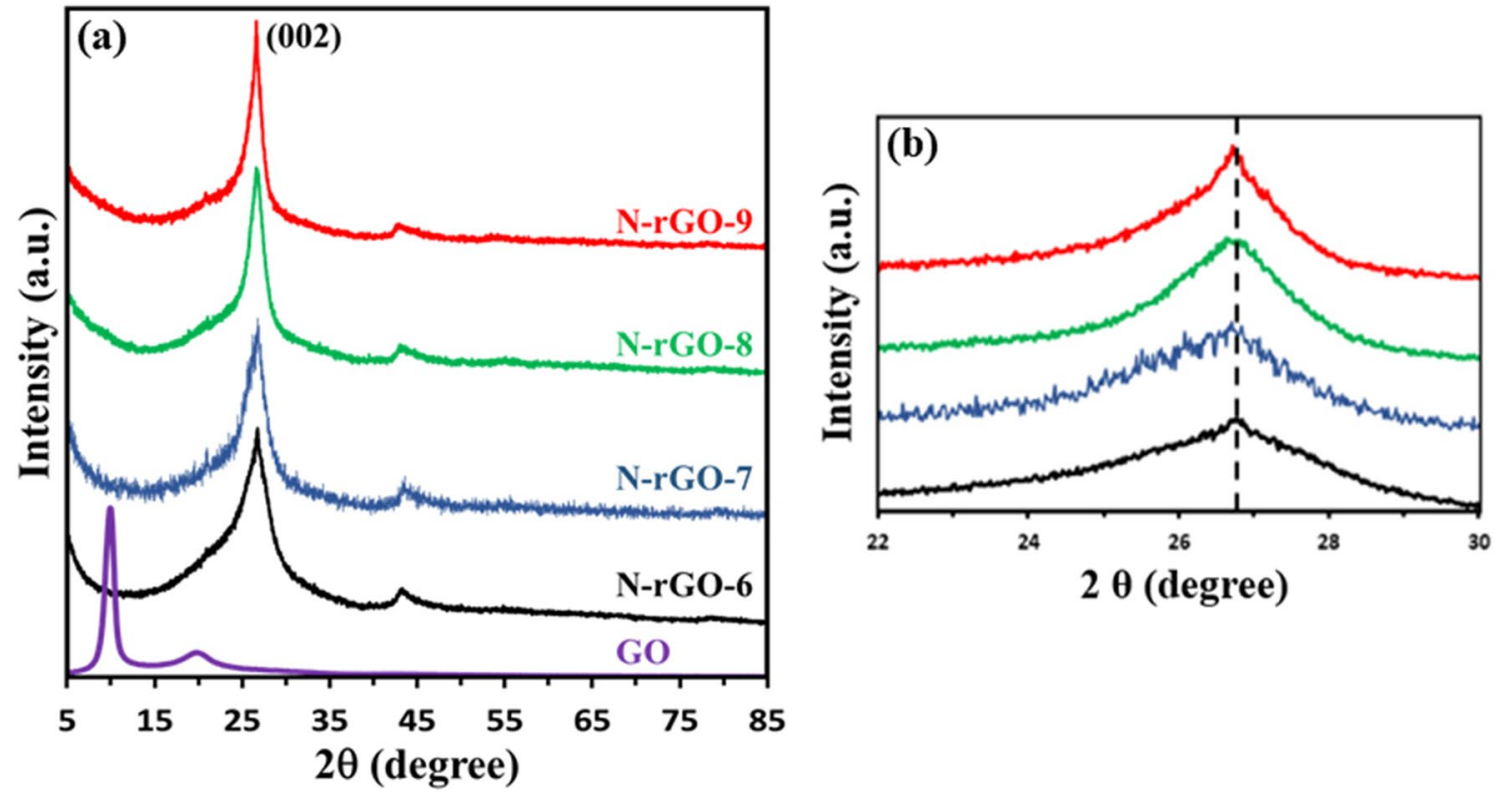

Fig. 2 XRD patterns of a GO and N-rGO samples; $\mathbf{b}$ Enlarged comparison of (002) diffraction plane of N-rGO samples

Table 1 The value of $\mathrm{d}$ spacing obtained from XRD for all $\mathrm{N}-\mathrm{rGO}$ samples \& crystallite size calculated from Scherrer's equation

\begin{tabular}{llc}
\hline Samples & $\mathrm{d}_{002}$ spacing $(\mathrm{nm})$ & $\begin{array}{l}\text { Crystallite } \\
\text { size, } \mathrm{L}_{\mathrm{c}}(\mathrm{nm})\end{array}$ \\
\hline GO & 0.89 & 28.77 \\
rGO-8 & 0.34 & 1.04 \\
N-rGO-6 & 0.33 & 3.12 \\
N-rGO-7 & 0.34 & 2.63 \\
N-rGO-8 & 0.33 & 3.44 \\
N-rGO-9 & 0.33 & 5.52 \\
\hline
\end{tabular}

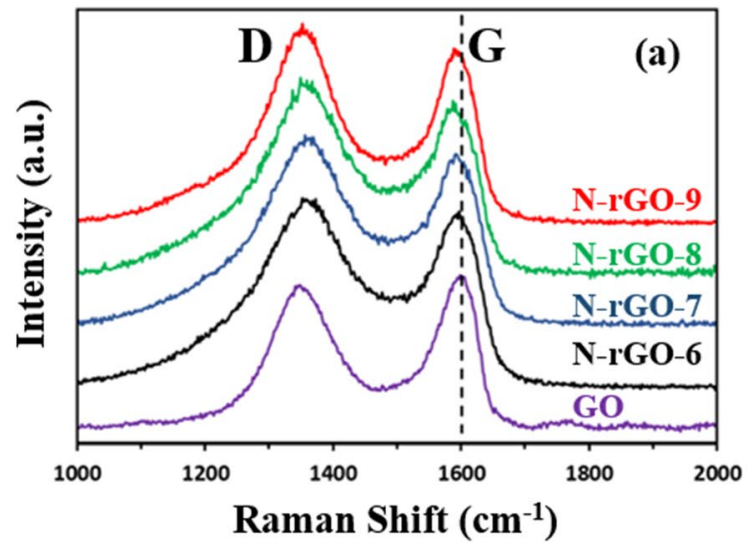

samples. The effect of crystallinity on supercapacitor performance will be discussed in the following section.

Structural and defect density change from nitrogen incorporation were investigated by Raman spectroscopy analysis. Figure 3a shows the comparative study of the Raman spectra for various $\mathrm{N}-\mathrm{rGO}$ samples. Here, two highintensity broad peaks, centered at $\sim 1350 \mathrm{~cm}^{-1}$ (D peak) and $1590 \mathrm{~cm}^{-1}$ (G peak) were observed. The D peak and $\mathrm{G}$ peak are generated from the breathing mode of the $\mathrm{sp}^{2}$ $C$ ring and in-plane $\mathrm{C}=\mathrm{C} \mathrm{sp}{ }^{2}$ bond vibration $[26,29]$. A redshift appeared in $\mathrm{G}$ peak from $\mathrm{GO}$ to $\mathrm{rGO}$ and further, $\mathrm{rGO}$ to $\mathrm{N}-\mathrm{rGO}$, as shown in Fig. S1 and 3a. The red-shift comes

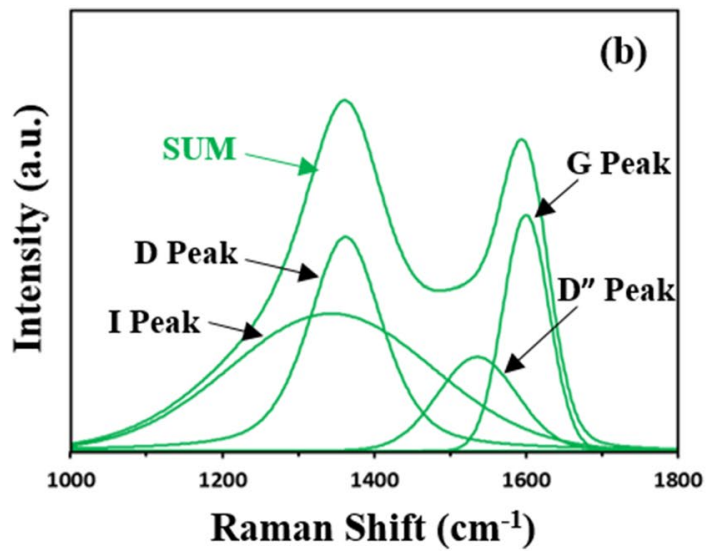

Fig. 3 a Raman spectra of various N-rGO samples; b Raman deconvolution of N-rGO-8 sample 
Table $2 \mathrm{I} / \mathrm{I}_{\mathrm{G}}$ ratio and calculated in-plane crystallite size for all the samples

\begin{tabular}{lll}
\hline Samples & $\mathrm{I}_{\mathrm{D}} / \mathrm{I}_{\mathrm{G}}$ & $\mathrm{L}_{\mathrm{a}}(\mathrm{nm})$ \\
\hline $\mathrm{GO}$ & $0.91 \pm 0.01$ & 21.13 \\
rGO-8 & $0.94 \pm 0.02$ & 20.45 \\
N-rGO-6 & $1.08 \pm 0.01$ & 17.80 \\
N-rGO-7 & $1.10 \pm 0.01$ & 17.48 \\
N-rGO-8 & $1.14 \pm 0.02$ & 16.86 \\
N-rGO-9 & $1.20 \pm 0.07$ & 16.02 \\
\hline
\end{tabular}

from two main reasons: (1) restoration of the conjugate structure of graphene during pyrolysis at high temperatures $[15,30]$ and (2) doping with a heteroatom (here, N) since $G$ peak is sensitive to charge carrier and dopant concentration in graphene lattices [31, 32]. The intensity ratio of $D$ and $G$ peaks $\left(I_{D} / I_{G}\right)$ is used to estimate the degree of disorderness and defects in graphene lattice [29]. Table 2 shows the $\mathrm{I}_{\mathrm{D}} / \mathrm{I}_{\mathrm{G}}$ ratio for $\mathrm{GO}, \mathrm{rGO}$, and all $\mathrm{N}$-rGO samples. The $I_{D} / I_{G}$ ratio for $N-r G O$ is higher than that of $G O$ and $r G O$ and the results indicate the creation of structural defects by (1) pyrolysis process, which leads to the cracking of $\mathrm{sp}^{2}$ carbon bonds and formation of smaller $\mathrm{sp}^{2}$ domains [14, 33 ] and (2) nitrogen doping into the lattice [15]. The inplane crystallite size $\left(L_{a}\right)$ of the synthesized samples was calculated following the work by Tunistra and Koenig [34] and is summarized in Table 2 . The crystallite size $\left(L_{a}\right)$ decreases with increasing pyrolysis temperature because a large number of lattice defects are induced due to the breakage of $\mathrm{N}$-rGO sheets during thermal decomposition of urea into $\mathrm{CO}_{2}$ and $\mathrm{NH}_{3}$ gas via formation of biuret $\left(\mathrm{C}_{2} \mathrm{H}_{5} \mathrm{~N}_{3} \mathrm{O}_{2}\right)$ and isocyanic acid (HNCO) $[22,35]$. The complex nature of induced defects in $\mathrm{N}-\mathrm{rGO}$ makes it difficult to fully understand the structure of doped graphene without deconvolution of the Raman spectrum. Therefore, we deconvoluted the Raman spectrum into four peaks, termed as I peak $\left(\sim 1340 \mathrm{~cm}^{-1}\right)$, D peak $\left(\sim 1360 \mathrm{~cm}^{-1}\right)$, D" peak $\left(\sim 1550 \mathrm{~cm}^{-1}\right)$ and $\mathrm{G}$ peak $\left(\sim 1600 \mathrm{~cm}^{-1}\right)$. A typically fitted Raman spectrum for N-rGO-8 is shown in Fig. $3 \mathrm{~b}$ and the summarized fitting results of other $\mathrm{N}-\mathrm{rGO}$ samples are provided in the online resource (Fig. S2). While the origin and significance of $D$ and $G$ peak are well understood $[26,29]$, I peak and D" peak are not well explored. I peak is observed as a shoulder to the $D$ peak on the spectrum of $\mathrm{N}$-doped carbon $[22,36]$ or highly disordered carbon, as observed by Angoni [37]. We found that the behavior of the I peak ratio is consistent with the $\mathrm{N}$ doping amount and the I peak ratio decreases with an increase in pyrolysis temperature (Table S1). The D" peak lies in between D and $G$ peak and has been identified as an indicator of stacking defects and crystallinity in graphene lattice [38]. T. Sharifi et al. mentioned an increase in D" peak with loss in $\mathrm{d}_{002}$ stacking [36] and S. Vollebregt et al. observed a decrease in D" peak with an increase in crystallinity [39]. These reports support our findings of decreasing D" peak with pyrolysis temperature, where crystallinity of $\mathrm{N}-\mathrm{rGO}$ sheets increased as consistent with XRD results in Fig. $2 \mathrm{~b}$. Another defect induced peak, D' peak was also reported in few studies $[30,40,41]$ as a shoulder peak to $\mathrm{G}$ peak. However, in our case, the $D^{\prime}$ and $G$ peak are found to be fully overlapping, as reported in a previous in-situ study [22]. Raman spectroscopy analysis depicted the dependence of deconvoluted I and D" peak on the nitrogen incorporation and crystallinity of the sample, respectively. This makes Raman spectroscopy and Raman deconvolution as a very strong tool for the characterization of $\mathrm{N}$-rGO samples, specifically temperature-dependent structural change.

We investigated the elemental composition and type of nitrogen functionalities in graphene lattice by XPS analysis. Figure 4a shows a comparison of survey scans for all N-rGO samples. The survey spectra confirm the presence of $\mathrm{C}, \mathrm{O}$, and $\mathrm{N}$ in $\mathrm{N}-\mathrm{rGO}$, with no other impurities. The high-resolution peak for $\mathrm{C} 1 \mathrm{~s}$ (Fig. 4b) can be deconvoluted into 5 bands corresponding to $\mathrm{sp}^{2} \mathrm{C}, \mathrm{C}=\mathrm{N} / \mathrm{C}-\mathrm{O}$, $\mathrm{C}-\mathrm{N} / \mathrm{C}=\mathrm{O}, \mathrm{O}-\mathrm{C}=\mathrm{O}$, and $\pi-\pi^{*}$, positioned at $284.5,285.6$, $287.0,289.3$, and $291.3 \mathrm{eV}$, respectively $[15,16,20,42]$. An increase in the $\mathrm{sp}^{2}$ carbon band is observed with pyrolysis temperature, because of nucleation of the new smaller $\mathrm{sp}^{2}$ nanodomains within the $\mathrm{sp}^{3}$ matrix during annealing and thermal decomposition of urea at a high temperature, whereas simultaneous decreasing the average size of the $\mathrm{sp}^{2}$ domain is also witnessed by calculated $\mathrm{L}_{\mathrm{a}}$ from Raman analysis $[14,15]$. Furthermore, the $\mathrm{N}-\mathrm{rGO}-8$ sample exhibits a broader $\mathrm{C} 1 \mathrm{~s}$ band (high FWHM) than rGO-8 (Fig. S3). The spectra change suggests successful nitrogen doping and formation of C-N species [31, 43, 44].

To probe nitrogen doping phenomena and its functionalities, high-resolution spectra for $\mathrm{N} 1 \mathrm{~s}$ peak were deconvoluted into 4 bands corresponding to pyridinic nitrogen (N-6), pyrrolic nitrogen (N-5), graphitic nitrogen (N-G), and oxidized nitrogen ( $\mathrm{N}-\mathrm{O}$ ) (Fig. $4 \mathrm{C}$ and Fig. S4). A gradual decrease in $\mathrm{N}$ content was observed (Table 3 ), along with the transformation of the $\mathrm{N} 1 \mathrm{~s}$ spectrum with pyrolysis temperature. The peak deconvolution analysis shown in Table 3 reveals variation in $\mathrm{N}-6, \mathrm{~N}-5, \mathrm{~N}-\mathrm{G}$, and $\mathrm{N}-\mathrm{O}$ content, as a decrease in $\mathrm{N}-6$ and $\mathrm{N}-5$ and an increase in N-G and $\mathrm{N}-\mathrm{O}$ with pyrolysis temperature, changes the peak shape of the $\mathrm{N} 1 \mathrm{~s}$ spectrum $[14,33,45]$.

From the above observations, we framed a possible mechanism of $\mathrm{N}$-doping. At lower pyrolysis temperature, the incoming nitrogen atom from urea interacts mostly with the oxygen functional groups present at the edges or defects of graphene lattice, and doped nitrogen forms $\mathrm{N}-5$ and N-6 functionalities. As the temperature increases, further removal of oxygen functional groups takes place, which leads to the partial removal of $\mathrm{N}-5$ and N-6 functionalities and simultaneously increase in N-G functionality, 
Table $3 \mathrm{~N}$-functionalities distribution and $\mathrm{C} / \mathrm{O}$ ratio in $\mathrm{N}$-rGO samples

\begin{tabular}{llllllc}
\hline Samples & N (at. \%) & N-6 (at. \%) & N-5 (at. \%) & N-G (at. \%) & N-O (at. \%) & C/O ratio \\
\hline N-rGO-6 & 15.0 & 28.6 & 40.7 & 23.4 & 7.2 & 9.9 \\
N-rGO-7 & 10.1 & 24.0 & 33.5 & 34.5 & 7.9 & 16.9 \\
N-rGO-8 & 8.7 & 23.6 & 22.3 & 45.2 & 8.8 & 23.0 \\
N-rGO-9 & 5.8 & 20.2 & 19.7 & 49.9 & 10.2 & 19.3 \\
\hline
\end{tabular}
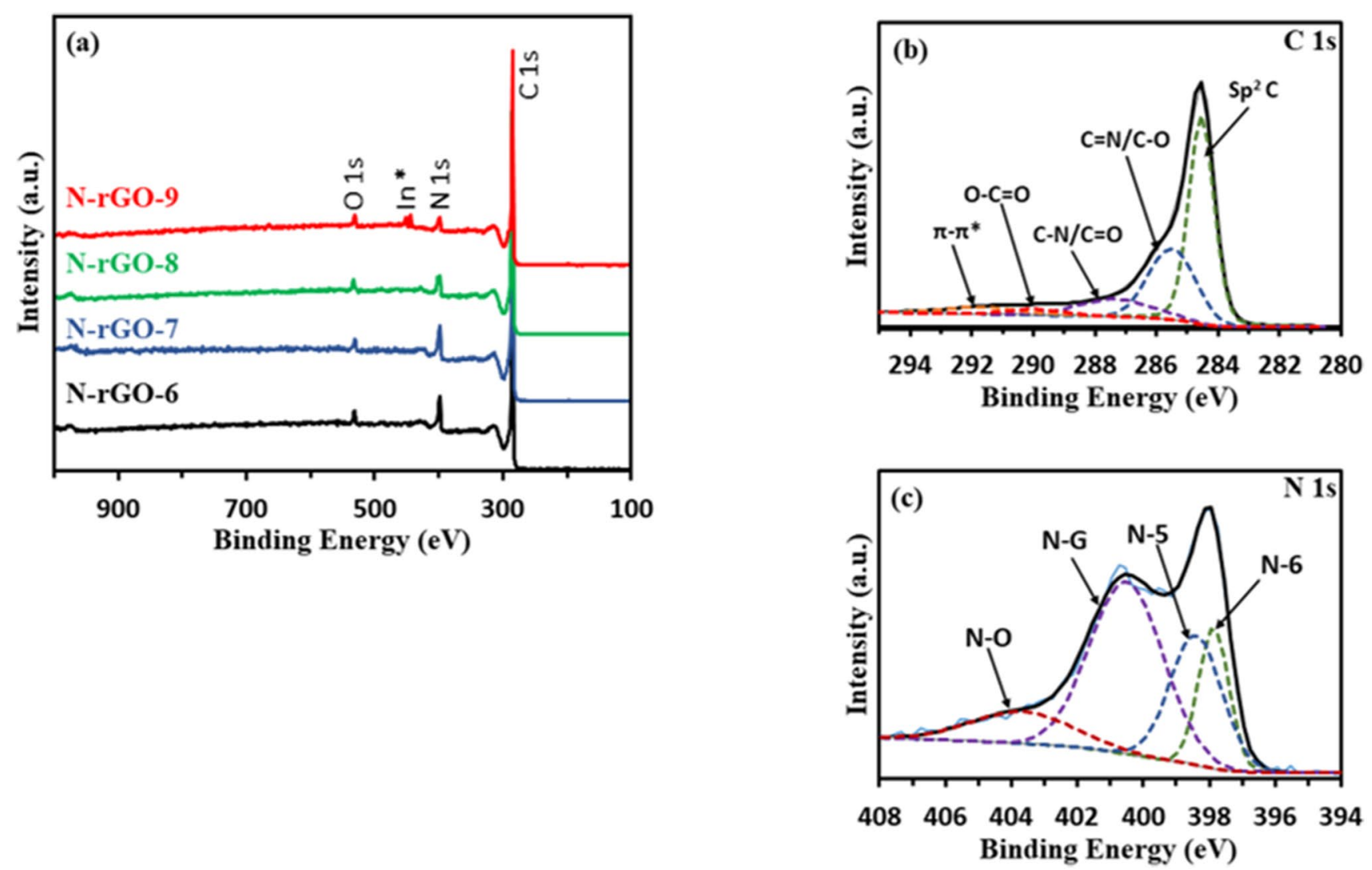

Fig. 4 a Survey scan of various $\mathrm{N}-\mathrm{rGO}$ samples ( $\mathrm{In}^{*}=$ Indium, from the substrate); $\mathbf{b}$ Expanded spectra of $\mathrm{C} 1 \mathrm{~s}$ peak and $\mathbf{c} \mathrm{N} 1 \mathrm{~s}$ peak of $\mathrm{N}-\mathrm{rGO}-8$

because of the high thermal stability of N-G $[15,46-48]$. It was also reported that the mechanical stability of the $\mathrm{N}$-rGO lattice comes dominantly from $\mathrm{N}-\mathrm{G}$ as compared to $\mathrm{N}-6$ and $\mathrm{N}-5$ [49] because once $\mathrm{N}$ is incorporated into the lattice, it is very difficult for $\mathrm{C}$ to replace them [50]. Hence, a higher temperature of pyrolysis is better for the formation of stable N-rGO with higher N-G content.

Morphological characterization and elemental mapping of the synthesized N-rGO were studied by TEM and SEM-EDX, respectively. Figure 5a shows a TEM image of the exfoliated N-rGO-8 sheet with a highly wrinkled structure at low magnification. The wrinkles in the $\mathrm{N}$-rGO sheet appear due to thermal treatment at high temperatures due to removed oxygen functional group and incorporated nitrogen. Interlayer spacing $(d=0.33 \mathrm{~nm})$ can be seen in the high-resolution micrograph, (inset) which matches that from XRD. SEM-EDX mapping (Fig. 5b) confirms the uniform and homogeneous doping of nitrogen along with the presence of $C$ and $O$ elements. The wrinkled and defective structure of $\mathrm{N}-\mathrm{rGO}$ will provide catalytically active sites for electrochemical reactions.

\subsection{Supercapacitor performance}

To investigate the electrochemical reaction and capacitive performance of the synthesized material as a supercapacitor electrode, $\mathrm{CV}$ was carried out in $0.5 \mathrm{M} \mathrm{H}_{2} \mathrm{SO}_{4}$ electrolyte. Quasi-rectangular CV profiles (Fig. 6a) with high double-layer capacity were observed for all N-rGO samples. The CV profile shows the presence of pseudocapacitive 

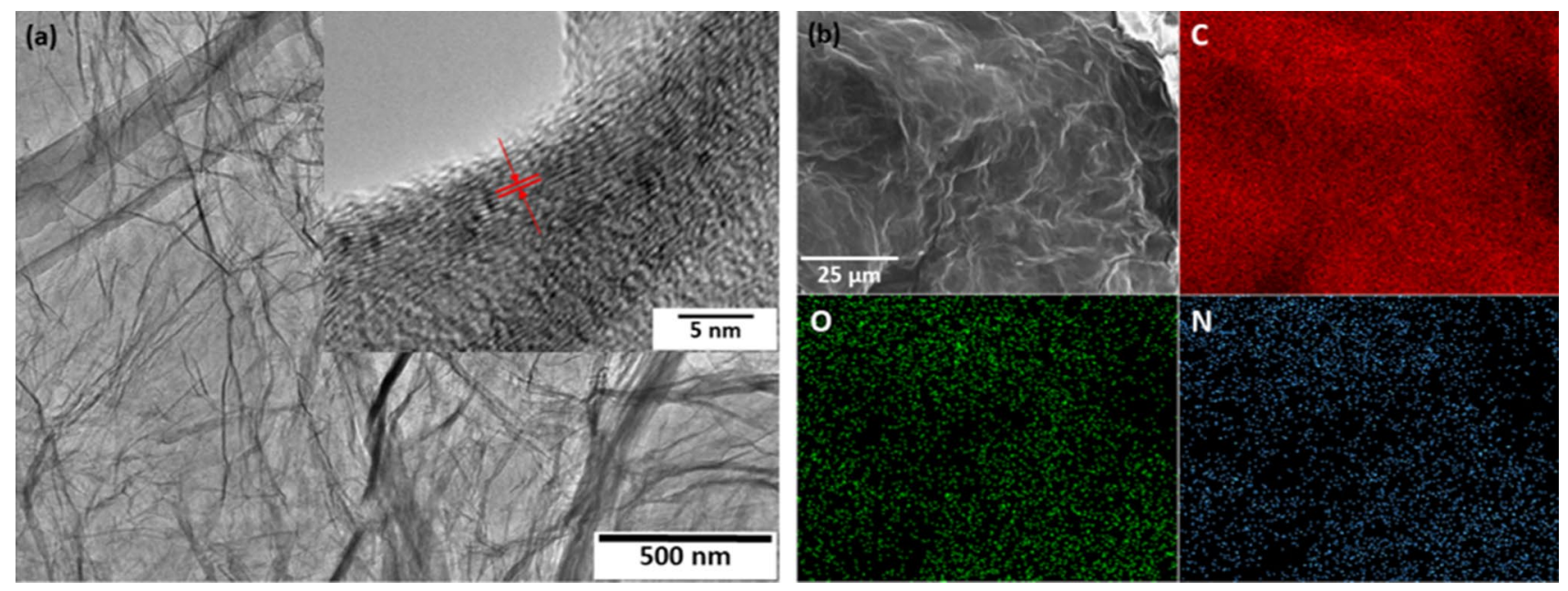

Fig. 5 a TEM micrograph of N-rGO-8 sample; $\mathbf{b}$ EDX analysis of N, C, and O in N-rGO-8
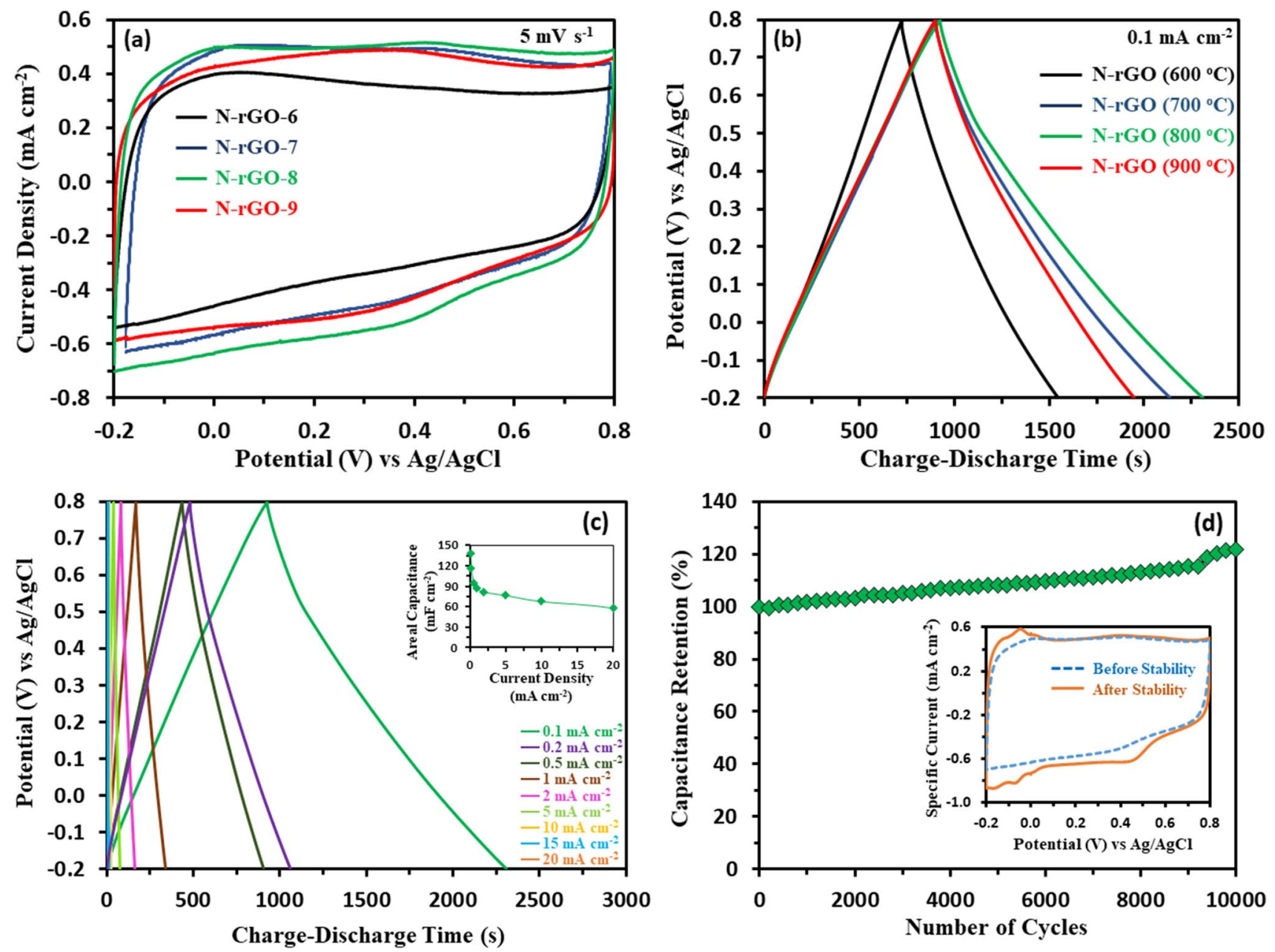

Fig. 6 a CV profile of $\mathrm{N}-\mathrm{rGO}$ samples at a scan rate of $5 \mathrm{mV} \mathrm{s}^{-1} ; \mathbf{b} \mathrm{GCD}$ at $0.1 \mathrm{~mA} \mathrm{~cm}{ }^{-2}$. c GCD of N-rGO-8 at various current densities; $\mathbf{d}$ Cyclic stability and inset: CV before and after stability of N-rGO-8 
behavior, indicated by the appearance of a broad and reversible redox peak between 0.2 and $0.5 \mathrm{~V}$. This pseudocapacitive contribution arises due to the redox reaction of $\mathrm{H}^{+}$species from electrolyte with the functional groups present on the electrode surface and has not been observed for organic (Fig. S10) or other types of electrolytes.[10, 12, 17]. Therefore, the corresponding reversible redox reaction of quinone to hydroquinone could be,

$\mathrm{C}_{6} \mathrm{H}_{4} \mathrm{O}_{2}+2 \mathrm{H}^{+}+2 \mathrm{e}^{-} \rightleftharpoons \mathrm{C}_{6} \mathrm{H}_{4}(\mathrm{OH})_{2}$

The CV profile indicates the partial presence of the electrochemically active species, which provide redox behavior, on the N-rGO samples. The largest capacity in the CV curve for the N-rGO-8 (Fig. 6a) indicates its superior capacitive performance than other samples. It would be interesting to correlate the effect of various physical parameters with the electrochemical performance of the electrode material. Crystallinity calculated from XRD and Raman D" peak was found to have a small effect on the charge storage capacity of the material, as reported previously [51-53]. In our case, N-rGO-9 has the highest crystallinity and largest crystallite size along the c-axis (XRD and D" Raman peak), while N-rGO-7 has the smallest. And the CV profile shows that $\mathrm{N}-\mathrm{rGO}-7$ has a high area under the $\mathrm{CV}$ curve than $\mathrm{N}-\mathrm{rGO}-9$. Thus, the low crystalline material with defects may show better charge storage capacity; however, it is not consistent for all the samples. Another important factor for $\mathrm{N}$-rGO is the degree of reduction, high reduction would allow easy ion intercalation. The obtained $\mathrm{CV}$ follows the same trend as observed from the calculated $\mathrm{C} / \mathrm{O}$ ratio (Table 3 ). The degree of reduction increases with pyrolysis temperature; however, above $800^{\circ} \mathrm{C}$, a further increase in pyrolysis temperature will lead to a large number of lattice defects in the N-rGO structure, as observed by BET (Fig. S5). A large number of lattice defects can also be interpreted from Raman and XPS analysis because at $900^{\circ} \mathrm{C}$ an increase in $I_{D} / I_{G}$ ratio (Table 2 ) and a decrease in $\mathrm{N}$ at \% (Table 3) is observed. Therefore the increased defect densities could mainly come from lattice defects and not from nitrogen induced defects $[33,45]$.

Figure $\mathrm{S} 6$ shows an increase in the double-layer current of the $\mathrm{CV}$ curve with an increased scan rate due to the rapid and fast diffusion of ions between the electrode surface and electrolyte [9]. The quasi-rectangular profile of N-rGO-8 was retained even at a high scan rate, showing the excellent rate capability and low resistance of the material.

rate, showing the excellent rate capability and low resistance of the material. To calculate the specific capacitance of the electrode material, galvanostatic charge-discharge (GCD) was carried out. Among all the synthesized
$\mathrm{N}$-rGO samples, $\mathrm{N}-\mathrm{rGO}-8$ shows the highest areal capacitance, $138.4 \mathrm{mF} \mathrm{cm}{ }^{-2}$, comparing with N-rGO-6 $(82.5 \mathrm{mF}$ $\left.\mathrm{cm}^{-2}\right)$, N-rGO-7 $\left(126.8 \mathrm{mF} \mathrm{cm}^{-2}\right), \mathrm{N}-\mathrm{rGO}-9\left(104.7 \mathrm{mF} \mathrm{cm}^{-2}\right)$ and $\mathrm{rGO}\left(42.7 \mathrm{mF} \mathrm{cm}^{-2}\right.$ ) at $0.1 \mathrm{~mA} \mathrm{~cm}^{-2}$ (Fig. $6 \mathrm{~b}$ and Fig. S7). The calculated areal capacitance is higher than that in most of the reported works on $\mathrm{N}$-doped carbon-based supercapacitor electrode material such as reactive laser synthesized $\mathrm{N}$-doped graphene $\left(9 \mathrm{mF} \mathrm{cm}^{-2}\right)$ [42], ammonia plasma-treated $\mathrm{N}-\mathrm{rGO}\left(9.5 \mathrm{mF} \mathrm{cm}^{-2}\right)[12], \mathrm{N}$-doped carbon nano-cage $\left(17.4 \mu \mathrm{F} \mathrm{cm}^{-2}\right)$ [54], N-doped hollow carbon nanofibers $\left(40 \mu \mathrm{F} \mathrm{cm}^{-2}\right)[55]$, and other non-doped carbon materials including CNT/rGO fiber $\left(0.98 \mathrm{mF} \mathrm{cm}^{-2}\right)$ [56], graphite cellulose $\left(2.3 \mathrm{mF} \mathrm{cm}{ }^{-2}\right)$ [57], activated carbon cloth $\left(76 \mathrm{mF} \mathrm{cm}^{-2}\right)$ [58], $\mathrm{rGO} / \mathrm{rGO}\left(71 \mathrm{mF} \mathrm{cm}^{-2}\right)$ [59], and $\mathrm{rGO} /$ cellulose $\left(81 \mathrm{mF} \mathrm{cm}^{-2}\right)[60]$. The GCD profile in Fig. $6 \mathrm{~b}$ shows a slight deviation from the perfect triangular shape of EDLC, which again confirms the presence of pseudocapacitive behavior at the electrode surface due to the reduction of quinone to hydroquinone (Eq. 1). Hence, the capacitive performance of the N-rGO electrodes is a mixture of both reversible pseudocapacitive and dominated EDLC behavior. This complex electrode system with nearly rectangular CV curve and predominant redox contribution have fast electrochemical kinetics (Fig. S6), enhanced capacitance, and can be used as a high-performance symmetric supercapacitor cell.

The variation of areal capacitance at specific current densities is plotted in Fig. 6c. Synthesized material showed good endurance even at a high current density of $20 \mathrm{~mA} \mathrm{~cm}{ }^{-2}$. Charge-discharge was further carried out for 10,000 cycles at a constant current density of $5 \mathrm{~mA} \mathrm{~cm}^{-2}$ (Fig. 6d). The material showed extraordinary performance with an increment of $21.7 \%$ in areal capacitance after 10,000 cycles of continuous charge-discharge between -0.2 and $0.8 \mathrm{~V}$ vs $\mathrm{Ag} / \mathrm{AgCl}$. Two main reasons are possible for the increased capacitance after stability test: (1) contribution of dissolved platinum (Pt) from the counter electrode in an acidic electrolyte and deposition on the working electrode [61], and (2) the electrochemical activation of a nitrogen functionality or oxygen functional group present at the electrode surface upon continuous cycling. Both are expected to result in the additional contribution of redox behavior. For a detailed understanding, CV was carried out after 10,000 cycles of GCD (inset Fig. 6d), where two new reversible redox peaks were observed between +0.1 and $-0.1 \mathrm{~V}$ potential, with an increase in peak intensity at around $0.5 \mathrm{~V}$.

To further understand the electrochemical kinetics, electrochemical impedance spectroscopy (EIS) was carried out within a frequency range of $500 \mathrm{kHz}$ to $10 \mathrm{mHz}$ with an imposed AC potential of $5 \mathrm{mV}$ (10 points per decade). Figure 7 a shows the Nyquist plot for all the samples $\mathrm{N}-\mathrm{rGO}-6, \mathrm{~N}-\mathrm{rGO}-7, \mathrm{~N}-\mathrm{rGO}-8$, and N-rGO-9. All the samples 

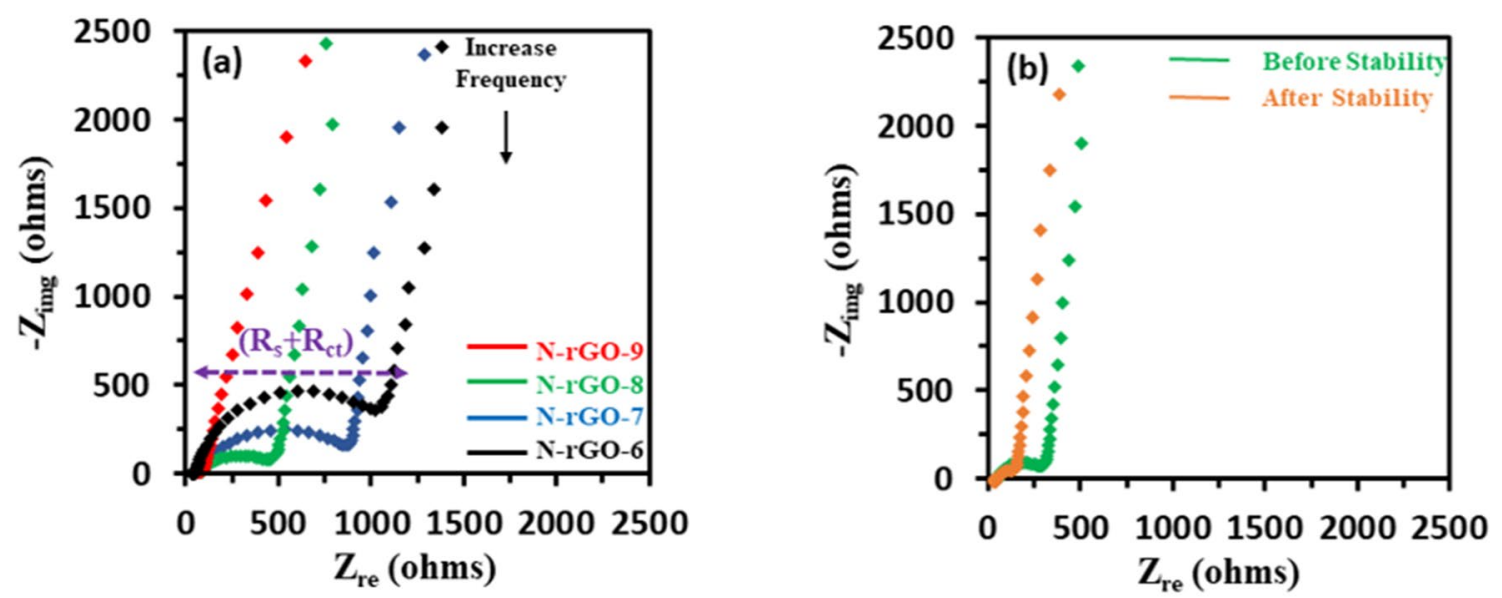

Fig. 7 a EIS analysis of N-rGO samples; $\mathbf{b}$ EIS before and after stability for N-rGO-8

showed the presence of a semicircle covering the high and mid-frequency region and a high ended tail at lower frequencies. The first high-frequency semicircle in the Nyquist plot represents the sum of the solution resistance $\left(R_{s}\right)$ of the cell and charge transfer resistance $\left(R_{c t}\right)$ of the reaction on the working electrode, which includes the intrinsic resistance of the electrode $\left(R_{e}\right)$, ionic resistance of the electrolyte $\left(R_{\infty}\right)$, and contact resistance between the electrode and current collector $\left(R_{c}\right)[3,62]$. The vertical line in the low-frequency region can be assigned to diffusion layer resistance or electric double-layer formation at the electrode [62]. The Nyquist plots for N-GO-6 and $\mathrm{N}$-rGO-7 show a semicircle with a large diameter due to high $\mathrm{R}_{\mathrm{s}}+\mathrm{R}_{\mathrm{ct}}$, which implies higher reaction resistance, as compared to N-rGO-8 and N-rGO-9, resulting in the low capacitive performance for these samples. Further, in the low-frequency region, N-rGO-8 has a steeper slope than all other samples showing better capacitor behavior due to enhanced ion accessibility and more electric double layer formation than other samples $[10,62]$. N-rGO-9 exhibits a smaller semicircle than $\mathrm{N}-\mathrm{rGO}-8$, yet low capacitance, since the specific surface area of $\mathrm{N}-\mathrm{rGO}-9\left(115.3 \mathrm{~m}^{2} \mathrm{~g}^{-1}\right)$ is lower than N-rGO-8 $\left(152.3 \mathrm{~m}^{2} \mathrm{~g}^{-1}\right)$, (Fig. S5) as estimated by the BET method. The lower surface area of N-rGO-9 can be attributed to the large number of lattice defects created at higher pyrolysis temperatures. Figure $7 \mathrm{~b}$ shows the comparative Nyquist plot before and after 10,000 cycles. The semicircle decreased after the stability test highlighting the decrease in $R_{s}+R_{c t}$, which could be the reason for increased capacitance after the stability test. However, the slope of initial N-rGO-8 is steeper than slope after stability test, depicting the decrease in EDLC formation and increased pseudocapacitive behavior after potential cycling.

\subsection{Symmetric supercapacitor performance}

Further, the N-rGO-8 electrodes were assembled in a symmetric supercapacitor cell (SSC) configuration, as schematically shown in Fig. 8a. The mass of both anode and cathode was kept the same, which was equal to the mass of active material used in the 3 electrode setup. Figure $8 \mathrm{~b}$ shows the CV profile of SSC between potential range -0.4 and $0.6 \mathrm{~V}$ at various scan rates ranging from 5 to $100 \mathrm{mV} \mathrm{s}^{-1}$. The CV profile in SSC had a large contribution from the pseudocapacitive behavior of surface functionalities as compared to the CV obtained from the 3 electrode setup (Fig. 6a). This is attributed to the appearance of the redox peak for the quinone functional group from each $\mathrm{N}$-rGO-8 electrode in SSC. Two broad and reversible redox peaks can be observed at a scan rate of $5 \mathrm{mV} \mathrm{s}^{-1}$ (Fig. $8 \mathrm{~b}$ : inset). In the case of SSC, the intrinsic potential of N-rGO is plotted in the $\mathrm{X}$-axis (unlike potential vs $\mathrm{Ag} / \mathrm{AgCl}$ in $\mathrm{X}$-axis for three-electrode setup) which gives rise to a slight shift in the position of the quinone redox peaks. Figure $8 \mathrm{c}$ shows the GCD curves of SSC at various specific current densities and confirms the deviation of SSC from ideal EDLC behavior due to redox reaction at both cathodic and anodic scan. The N-rGO-8 symmetric cell showed a maximum specific capacitance of $66.8 \mathrm{~F} \mathrm{~g}^{-1}$ at $0.1 \mathrm{~A} \mathrm{~g}^{-1}$. EIS was also carried out (Fig. 8d) under similar conditions as carried out in 3 electrode setup. EIS analysis of SSC showed higher $R_{s}+R_{c t}$ as compare to that of three-electrode system, which could be due to various reasons, such as (1) low electrical conductivity of current collector (stainless steel), (2) high contact resistance between active material (N-rGO-8) and current collector, and (3) low wettability of 
(a)
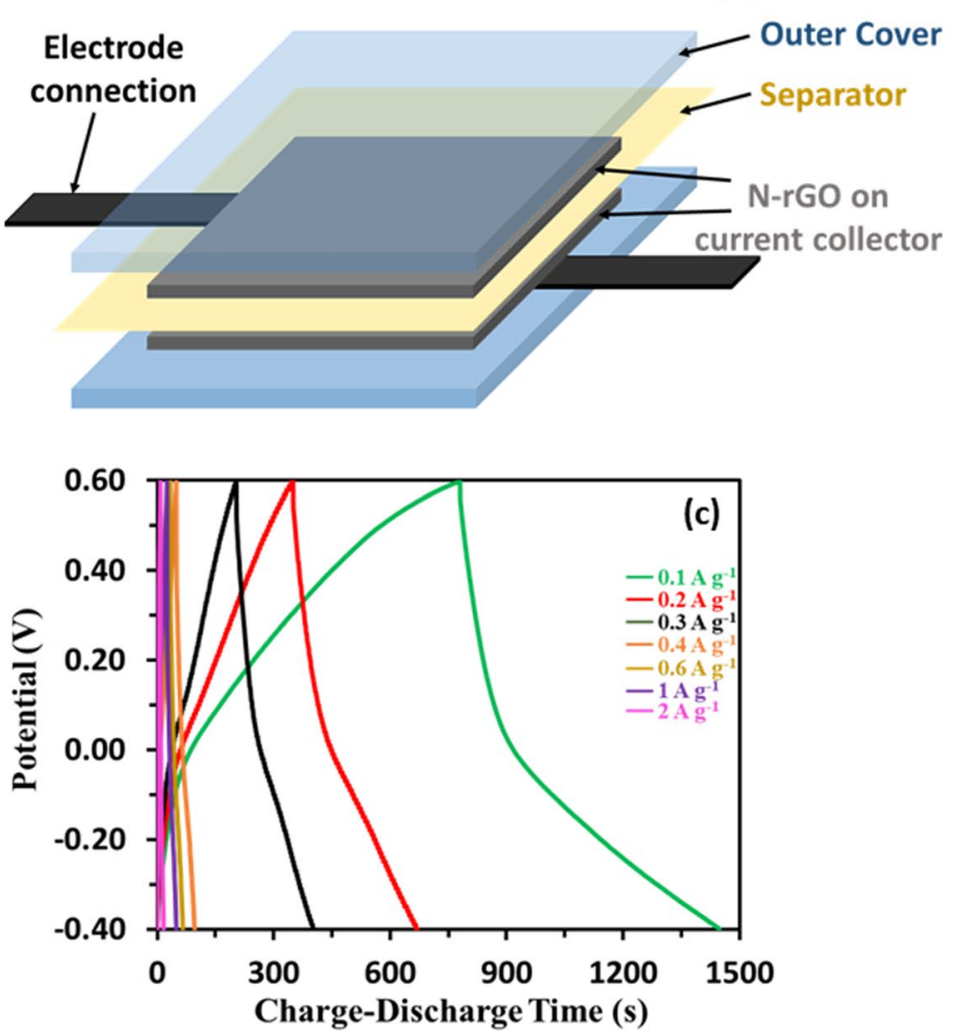
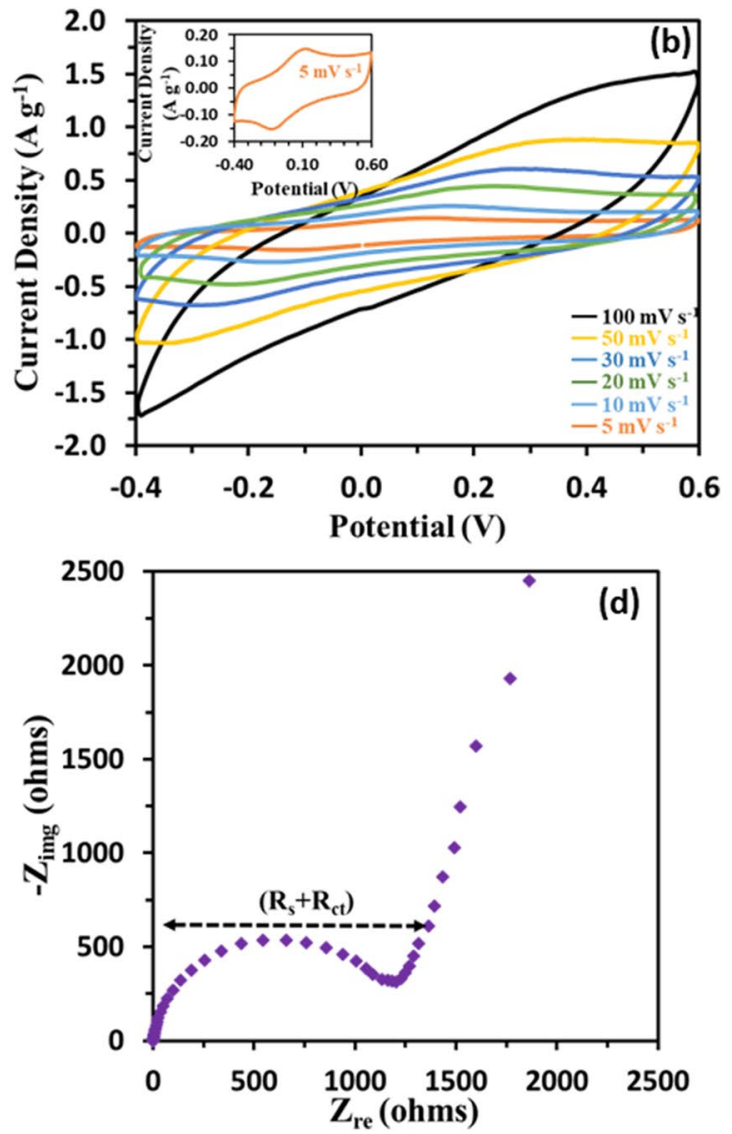

Fig. 8 a Schematic representation of two-electrode setup; b CV profile at various scan rates and inset: CV at 5 mV s $\mathrm{s}^{-1}$ c GCD at different current densities; and $\mathbf{d}$ EIS analysis of SSC

separator (filter paper) in electrolyte leading to poor contact with the electrodes [63]. However, the vertical line in the low-frequency region suggests the enhanced pseudocapacitive behavior in the symmetric supercapacitor cell. Additionally, self-discharge and leak current in symmetric supercapacitor cell were also reported in online resources Fig. S8 and S9.

\section{Conclusion}

In conclusion, $\mathrm{N}-\mathrm{rGO}$ was synthesized via simultaneous $\mathrm{N}$-doping and thermal reduction at $600-900{ }^{\circ} \mathrm{C}$ in the presence of urea. In this wide temperature range, the structural and chemical change in N-rGO crystal were investigated by techniques such as XRD, XPS, and Raman spectroscopy, and the nitrogen doping mechanism was deduced. Deconvolution of Raman spectrum identified new peaks (I and D" peak) along with conventional $D$ and $G$ peaks, assigned to the crystallinity and dopant concentration, which was further confirmed by XRD and XPS. XPS analysis showed that the presence of functional groups in $\mathrm{rGO}$ provides active sites for nitrogen to incorporate into the lattice. However, at higher pyrolysis temperatures, along with oxygen functional groups, the removal of nitrogen was also observed. $\mathrm{N}$-rGO synthesized at $800^{\circ} \mathrm{C}$ showed the highest areal capacitance and excellent stability due to the large surface area, high C/O ratio, low crystallinity, 8.7 at. \% nitrogen doping, and the potential-dependent activation of the functional group. EIS also confirmed the superiority of $800{ }^{\circ} \mathrm{C}$ pyrolysis temperature due to low solution resistance and reduced charge transfer resistance with dominant electric double layer formation. The material was further tested in a symmetric supercapacitor cell in aqueous electrolyte showing high specific capacitance $\left(66.8 \mathrm{~F} \mathrm{~g}^{-1}\right)$, arising from the synergistic effect of EDLC and pseudocapacitive behavior. The above characterizations reveal the advanced supercapacitor behavior of the material. Further, real-time characterizations (such as in-situ techniques) in commercially feasible electrolytes (like organic and ionic electrolytes) are essential for complete optimization and practical usage of the $\mathrm{N}-\mathrm{rGO}$ as a supercapacitor electrode. 
Acknowledgements This work was supported by Strategic Research Foundation Grant-aided Project for Private Universities and JSPS KAKENHI Grant Number 17K05969 from the Ministry of Education, Culture, Sports, Science, and Technology, Japan (MEXT).

Author contributions RY carried out the major research work and drafted the manuscript. PJ helped in the TEM and EIS analysis. TY and $\mathrm{SH}$ carried out the BET analysis of all the $\mathrm{N}-\mathrm{rGO}$ samples. $\mathrm{MH}$ and MY supervised and guided during the research work.

\section{Compliance with ethical standards}

Conflicts of interest The authors declare no conflict of interest.

Data and Code Availability Not applicable.

\section{References}

1. Kötz R, Carlen M (2000) Principles and applications of electrochemical capacitors. Electrochim Acta. https://doi.org/10.1016/ S0013-4686(00)00354-6

2. Yoneda D, Suzuki S, Hiramoto S, Matsuoka $Y$, Hara M, Yoshimura M (2019) Growth of vertically-aligned carbon nanotubes on graphite for electric double-layer capacitors. Mater Res Express. https://doi.org/10.1088/2053-1591/ab23dc

3. Bhojane P, Sen S, Shirage PM (2016) Enhanced electrochemical performance of mesoporous $\mathrm{NiCo} 2 \mathrm{O} 4$ as an excellent supercapacitive alternative energy storage material. Appl Surf Sci. https ://doi.org/10.1016/j.apsusc.2016.03.167

4. Lee JU, Yoon D, Cheong H (2012) Estimation of young's modulus of graphene by Raman spectroscopy. Nano Lett. https://doi. org/10.1021/nl301073q

5. Stoller MD, Park S, Yanwu Z, An J, Ruoff RS (2008) GrapheneBased ultracapacitors. Nano Lett. https://doi.org/10.1021/nl802 $558 y$

6. Xu Y, Sheng K, Li C, Shi G (2010) Self-assembled graphene hydrogel via a one-step hydrothermal process. ACS Nano. https://doi. org/10.1021/nn101187z

7. Song X, Wang S, Bao Y, Liu G, Sun W, Ding LX, Liu H, Wang H (2017) A high strength, free-standing cathode constructed by regulating graphitization and the pore structure in nitrogendoped carbon nanofibers for flexible lithium-sulfur batteries. J Mater Chem A. https://doi.org/10.1039/C7TA01171G

8. Han S, Wu D, Li S, Zhang F, Feng X (2014) Porous graphene materials for advanced electrochemical energy storage and conversion devices. Adv Mater. https://doi.org/10.1002/adma.20130 3115

9. Verma M, Yadav R, Sinha L, Mali SS, Hong CK, Shirage PM (2018) Pseudocapacitive-battery-like behavior of cobalt manganese nickel sulfide (CoMnNiS) nanosheets grown on Ni-foam by electrodeposition for realizing high capacity. RSC Adv. https://doi. org/10.1039/C8RA07471B

10. Sun L, Wang L, Tian C, Tan T, Xie Y, Shi K, Li M, Fu H (2012) Nitrogen-doped graphene with high nitrogen level via a one-step hydrothermal reaction of graphene oxide with urea for superior capacitive energy storage. RSC Adv. https://doi.org/10.1039/ c2ra01367c

11. Paek E, Pak AJ, Kweon KE, Hwang GS (2013) On the origin of the enhanced supercapacitor performance of nitrogen-doped graphene. J Phys Chem C. https://doi.org/10.1021/jp312490q

12. Nolan H, Mendoza-Sanchez B, Ashok Kumar N, McEvoy N, O’Brien S, Nicolosi V, Duesberg GS (2014) Nitrogen-doped reduced graphene oxide electrodes for electrochemical supercapacitors. Phys Chem Chem Phys. https://doi.org/10.1039/ c3cp54877e

13. Joshi P, Huang HH, Yadav R, Hara M, Yoshimura M (2020) Borondoped Graphene as Electrocatalytic Support for Iridium Oxide for Oxygen Evolution Reaction. Catal Sci Technol. https://doi. org/10.1039/D0CY00919A

14. Putri LK, Ng BJ, Ong WJ, Lee HW, Chang WS, Chai SP (2017) Heteroatom Nitrogen- and Boron-Doping as a Facile Strategy to Improve Photocatalytic Activity of Standalone Reduced Graphene Oxide in Hydrogen Evolution. ACS Appl Mater Interfaces 9:4558-4569. https://doi.org/10.1021/acsami.6b12060

15. Lin Z, Waller G, Liu Y, Liu M, Wong CP (2012) Facile synthesis of nitrogen-doped graphene via pyrolysis of graphene oxide and urea, and its electrocatalytic activity toward the oxygenreduction reaction. Adv Energy Mater. https://doi.org/10.1002/ aenm.201200038

16. Duan $X$, Ao Z, Sun $H$, Indrawirawan $S$, Wang $Y$, Kang J, Liang $F$, Zhu ZH, Wang S (2015) Nitrogen-doped graphene for generation and evolution of reactive radicals by metal-free catalysis. ACS Appl Mater Interfaces. https://doi.org/10.1021/am508416n

17. Li Y, Liu L, Wu Y, Wu T, Wu H, Cai Q, Xu Y, Zeng B, Yuan C, Dai L (2019) Facile synthesis of nitrogen-doped carbon materials with hierarchical porous structures for high-performance supercapacitors in both acidic and alkaline electrolytes. J Mater Chem A. https://doi.org/10.1039/c9ta00890j

18. Hara M, Badam R, Wang GJ, Huang HH, Yoshimura M (2018) Synthesis and evaluation of iridium oxide nanoparticle catalysts supported on nitrogen-doped reduced graphene oxides. ECS Trans. https://doi.org/10.1149/08511.0027ecst

19. Lemes G, Sebastián D, Pastor E, Lázaro MJ (2019) N-doped graphene catalysts with high nitrogen concentration for the oxygen reduction reaction. J Power Sources. https://doi. org/10.1016/j.jpowsour.2019.227036

20. Zhang Y, Ge J, Wang L, Wang D, Ding F, Tao X, Chen W (2013) Manageable $\mathrm{N}$-doped graphene for high performance oxygen reduction reaction. Sci Rep. https://doi.org/10.1038/srep02771

21. Xing Z, Ju Z, Zhao Y, Wan J, Zhu Y, Qiang Y, Qian Y (2016) One-pot hydrothermal synthesis of Nitrogen-doped graphene as highperformance anode materials for lithium ion batteries. Sci Rep. https://doi.org/10.1038/srep26146

22. Mowry M, Palaniuk D, Luhrs CC, Osswald S (2013) Insitu Raman spectroscopy and thermal analysis of the formation of nitrogendoped graphene from urea and graphite oxide. RSC Adv. https ://doi.org/10.1039/c3ra42725k

23. Hummers WS, Offeman RE (1958) Preparation of Graphitic Oxide. J Am Chem Soc. https://doi.org/10.1021/ja01539a017

24. Krishnamoorthy K, Veerapandian M, Yun K, Kim SJ (2013) The chemical and structural analysis of graphene oxide with different degrees of oxidation. Carbon N Y. https://doi.org/10.1016/j. carbon.2012.10.013

25. Chua CK, Pumera M (2014) Chemical reduction of graphene oxide: A synthetic chemistry viewpoint. Chem Soc Rev. https:// doi.org/10.1039/c3cs60303b

26. Huang $\mathrm{HH}$, De Silva KKH, Kumara GRA, Yoshimura M (2018) Structural Evolution of Hydrothermally Derived Reduced Graphene Oxide. Sci Rep. https://doi.org/10.1038/s41598-01825194-1

27. Wong CPP, Lai CW, Lee KM, Abd Hamid SB (2015) Advanced chemical reduction of reduced graphene oxide and its photocatalytic activity in degrading reactive black 5. Materials (Basel). https://doi.org/10.3390/ma8105363

28. Botas $C$, Álvarez P, Blanco C, Santamaría R, Granda M, Gutiérrez MD, Rodríguez-Reinoso F, Menéndez R (2013) Critical temperatures in the synthesis of graphene-like materials by thermal 
exfoliation-reduction of graphite oxide. Carbon N Y. https://doi. org/10.1016/j.carbon.2012.09.059

29. De Silva KKH, Huang HH, Suzuki S, Badam R, Yoshimura M (2018) Ethanol-assisted restoration of graphitic structure with simultaneous thermal reduction of graphene oxide. Jpn J Appl Phys https://doi.org/10.7567/JJAP.57.08NB03

30. Kudin KN, Ozbas B, Schniepp HC, Prud'homme RK, Aksay IA, Car $R$ (2008) Raman spectra of graphite oxide and functionalized graphene sheets. Nano Lett. https://doi.org/10.1021/nl071822y

31. Li X, Wang H, Robinson JT, Sanchez H, Diankov G, Dai H (2009) Simultaneous nitrogen doping and reduction of graphene oxide. J Am Chem Soc. https://doi.org/10.1021/ja907098f

32. Deng D, Pan X, Yu L, Cui Y, Jiang Y, Qi J, Li WX, Fu Q, Ma X, Xue Q, Sun G, Bao X (2011) Toward N-doped graphene via solvothermal synthesis. Chem Mater. https://doi.org/10.1021/cm102666r

33. Li XF, Lian KY, Liu L, Wu Y, Qiu Q, Jiang J, Deng M, Luo Y (2016) Unraveling the formation mechanism of graphitic nitrogendoping in thermally treated graphene with ammonia. Sci Rep. https://doi.org/10.1038/srep23495

34. Tuinstra F, Koenig JL (1970) Raman Spectrum of Graphite. J Chem Phys. https://doi.org/10.1063/1.1674108

35. Brack W, Heine B, Birkhold F, Kruse M, Schoch G, Tischer S, Deutschmann O (2014) Kinetic modeling of urea decomposition based on systematic thermogravimetric analyses of urea and its most important by-products. Chem Eng Sci. https://doi. org/10.1016/j.ces.2013.11.013

36. Sharifi T, Nitze F, Barzegar HR, Tai CW, Mazurkiewicz M, Malolepszy A, Stobinski L, Wågberg T (2012) Nitrogen doped multi walled carbon nanotubes produced by CVD-correlating XPS and Raman spectroscopy for the study of nitrogen inclusion. Carbon N Y. https://doi.org/10.1016/j.carbon.2012.03.022

37. Angoni K (1993) Remarks on the structure of carbon materials on the basis of Raman spectra. Carbon N Y. https://doi. org/10.1016/0008-6223(93)90106-K

38. Claramunt $S$, Varea A, López-Díaz D, Velázquez MM, Cornet A, Cirera A (2015) The importance of interbands on the interpretation of the raman spectrum of graphene oxide. J Phys Chem C. https://doi.org/10.1021/acs.jpcc.5b01590

39. Vollebregt S, Ishihara R, Tichelaar FD, Hou Y, Beenakker CIM (2012) Influence of the growth temperature on the first and second-order Raman band ratios and widths of carbon nanotubes and fibers. Carbon N Y. https://doi.org/10.1016/j.carbo n.2012.03.026

40. Ferrari AC (2007) Raman spectroscopy of graphene and graphite: Disorder, electron-phonon coupling, doping and nonadiabatic effects. Solid State Commun. https://doi.org/10.1016/j. ssc.2007.03.052

41. Malard LM, Pimenta MA, Dresselhaus G, Dresselhaus MS (2009) Raman spectroscopy in graphene. Phys Rep. https://doi. org/10.1016/j.physrep.2009.02.003

42. Pérez Del Pino Á, Martínez Villarroya A, Chuquitarqui A, Logofatu C, Tonti D, György E (2018) Reactive laser synthesis of nitrogendoped hybrid graphene-based electrodes for energy storage. J Mater Chem A. https://doi.org/10.1039/c8ta03830a

43. Stankovich S, Dikin DA, Piner RD, Kohlhaas KA, Kleinhammes A, Jia Y, Wu Y, Nguyen SBT, Ruoff RS (2007) Synthesis of graphenebased nanosheets via chemical reduction of exfoliated graphite oxide. Carbon N Y. https://doi.org/10.1016/j.carbon.2007.02.034

44. von Sturm F (1988) Carbon Materials. Carbon-Electrochemical and Physicochemical Properties by K. Kinoshita. Wiley, New York, pp 533. https://doi.org/10.1002/ange.19881000944
45. Hou Z, Terakura K (2015) Effect of nitrogen doping on the migration of the carbon adatom and monovacancy in graphene. $J$ Phys Chem C. https://doi.org/10.1021/jp512886t

46. Share K, Cohn AP, Carter R, Rogers B, Pint CL (2016) Role of Nitrogen-doped graphene for improved high-capacity potassium ion battery anodes. ACS Nano. https://doi.org/10.1021/ acsnano.6b05998

47. Lin Z, Waller GH, Liu Y, Liu M, pingWong C (2013) 3D Nitrogendoped graphene prepared by pyrolysis of graphene oxide with polypyrrole for electrocatalysis of oxygen reduction reaction. Nano Energy. https://doi.org/10.1016/j.nanoen.2012.09.002

48. Cho YJ, Kim HS, Im H, Myung Y, Jung GB, Lee CW, Park J, Park MH, Cho J, Kang HS (2011) Nitrogen-doped graphitic layers deposited on silicon nanowires for efficient lithium-ion battery anodes. J Phys Chem C. https://doi.org/10.1021/jp201485j

49. Senturk AE, Oktem AS, Konukman AES (2018) Influence of defect locations and nitrogen doping configurations on the mechanical properties of armchair graphene nanoribbons. J Mol Model. https://doi.org/10.1007/s00894-018-3581-3

50. Wang L, Zhang X, Yan F, Chan HLW, Ding F (2016) Mechanism of boron and nitrogen in situ doping during graphene chemical vapor deposition growth. Carbon N Y. https://doi.org/10.1016/j. carbon.2015.11.058

51. Ramesh TN, Vishnu Kamath P (2009) The effect of "crystallinity" and structural disorder on the electrochemical performance of substituted nickel hydroxide electrodes. J Solid State Electrochem. https://doi.org/10.1007/s10008-008-0591-6

52. Peng W, Han G, Huang Y, Cao Y, Song S (2018) Insight the effect of crystallinity of natural graphite on the electrochemical performance of reduced graphene oxide. Results Phys. https://doi. org/10.1016/j.rinp.2018.08.055

53. Yoo H-M, Heo G-Y, Park S-J (2011) Effect of crystallinity on the electrochemical properties of carbon black electrodes. Carbon Lett. https://doi.org/10.5714/CL.2011.12.4.252

54. Zhao J, Lai H, Lyu Z, Jiang Y, Xie K, Wang X, Wu Q, Yang L, Jin Z, Ma Y, Liu J, Hu Z (2015) Hydrophilic hierarchical nitrogen-doped carbon nanocages for ultrahigh supercapacitive performance. Adv Mater. https://doi.org/10.1002/adma.201500945

55. Zhan C, Xu Q, Yu X, Liang Q, Bai Y, Huang ZH, Kang F (2016) Nitrogen-rich hierarchical porous hollow carbon nanofibers for high-performance supercapacitor electrodes. RSC Adv. https:// doi.org/10.1039/c6ra07128g

56. Cheng H, Dong Z, Hu C, Zhao Y, Hu Y, Qu L, Chen N, Dai L (2013) Textile electrodes woven by carbon nanotube-graphene hybrid fibers for flexible electrochemical capacitors. Nanoscale. https ://doi.org/10.1039/c3nr00320e

57. Zheng G, Hu L, Wu H, Xie X, Cui Y (2011) Paper supercapacitors by a solvent-free drawing method, Energy Environ. Sci. https:// doi.org/10.1039/c1ee01853a

58. Wang G, Wang H, Lu X, Ling Y, Yu M, Zhai T, Tong Y, Li Y (2014) Solid-state supercapacitor based on activated carbon cloths exhibits excellent rate capability. Adv Mater. https://doi. org/10.1002/adma.201304756

59. Xiong Z, Liao C, Han W, Wang X (2015) Mechanically tough largearea hierarchical porous graphene films for high-performance flexible supercapacitor applications. Adv Mater. https://doi. org/10.1002/adma.201501983

60. Weng Z, Su Y, Wang DW, Li F, Du J, Cheng HM (2011) Graphenecellulose paper flexible supercapacitors. Adv Energy Mater. https://doi.org/10.1002/aenm.201100312

61. Do CL, Pham TS, Nguyen NP, Tran VQ (2013) Properties of Pt/C nanoparticle catalysts synthesized by electroless deposition 
for proton exchange membrane fuel cell. Adv Nat Sci Nanosci Nanotechnol. https://doi.org/10.1088/2043-6262/4/3/035011

62. Mei BA, Munteshari O, Lau J, Dunn B, Pilon L (2018) Physical Interpretations of Nyquist Plots for EDLC Electrodes and Devices. J Phys Chem C. https://doi.org/10.1021/acs.jpcc.7b10582

63. Sun XZ, Zhang X, Huang B, Ma YW (2014) Effects of separator on the electrochemical performance of electrical double-layer capacitor and hybrid battery-supercapacitor, Wuli Huaxue
Xuebao/ Acta Phys.- Chim. Sin. https://doi.org/10.3866/PKU. WHXB201401131

Publisher's Note Springer Nature remains neutral with regard to jurisdictional claims in published maps and institutional affiliations. 